\title{
Fused deposition modelling (FDM) of composites of graphene nanoplatelets and polymers for high thermal conductivity: a mini-review
}

\author{
Valentina Guerra, Chaoying Wan and Tony McNally
}

\begin{abstract}
Composites of polymers and the graphene family of 2D materials continue to attract great interest due their potential to dissipate heat, thus extending the in-service life of electronic and other devices. Such composites can be 3D printed using Fused Deposition Modelling into complex bespoke structures having enhanced properties, including thermal conductivity in different directions. While there are controversial opinions on the limitations of FDM for large-scale and high volume production (e.g. long production times, and expensive printers required), FDM is an innovative solution to the manufacture of small objects where effective thermal management is required and it is a valid alternative for the manufacture of (micro)-electronic components. There are few papers published on the FDM of functional composite materials based on graphene(s). In this mini-review, we describe the many technical challenges that remain to successful printing of these composites by FDM, including orientation effects, void formation, printing and feeding rates, nozzle and printing bed temperatures and the role each has in determining the thermal conductivity of any composite product made by FDM. We also compare these initial reports with those on FDM of other and related carbonaceous fillers, such as multi-walled carbon nanotubes and carbon fibre.
\end{abstract}

Keywords: 3D printing, Fused deposition modelling (FDM), Composites, Graphene nanoplatelets (GNP), Multi-walled carbon nanotubes (MWCNTs), Carbon fibre (CF), Polymers, Thermal conductivity (TC)

\section{Introduction}

The need for flexible devices driven by the exigence to fulfil requirements from an immense variety of customers is pushing technology companies towards the manufacture of soft substrates, which can be folded, rolled, are portable and environmentally friendly (e.g. recyclable, low energy consuming and low waste). Flexible nanotechnology is considered a new frontier for the production of what are by now considered "primary" goods such as smart phones, tablets and computers, in particular towards the idea to "transform" one object into another by simple folding, connecting them or rolling

\footnotetext{
*Correspondence: t.mcnally@warwick.ac.uk

International Institute for Nanocomposite Manufacturing (IINM), WMG, University of Warwick, Coventry CV4 7AL, UK
}

them. However, when scaling down the dimensions of an object, for instance in an electronic device, the heat generated during operation can represent an issue if the material the device is made from is not able to efficiently dissipate heat. Indeed, the excess heat trapped inside the object might lead to thermal degradation [1-5].

Composites of graphene nanoplatelets (GNP) and polymers continue to arouse great interest as possible route to dissipating heat, thus extending the in-service life of the final product. In a crystalline material (regular homogeneous structure) the phonons propagates as harmonic waves and the heat dissipates with no energy loss along the thermal path. In polymeric systems, the amorphous regions generates discontinuities (heterogeneous points) where the phonons scatter, thus, disrupting the thermal

\section{Springer Open}

(c) The Author(s). 2020 Open Access This article is licensed under a Creative Commons Attribution 4.0 International License, which permits use, sharing, adaptation, distribution and reproduction in any medium or format, as long as you give appropriate credit to the original author(s) and the source, provide a link to the Creative Commons licence, and indicate if changes were made. The images or other third party material in this article are included in the article's Creative Commons licence, unless indicated otherwise in a credit line to the material. If material is not included in the article's Creative Commons licence and your intended use is not permitted by statutory regulation or exceeds the permitted use, you will need to obtain permission directly from the copyright holder. To view a copy of this licence, visit http://creativecommons.org/licenses/by/4.0/. 
path [6] (and references therein). For that reason, polymers are thermal insulators yet the addition of functional fillers such as GNPs, which are thermal conductors, to polymers may allow the manufacturing of thermally conductive composites. The basic concept is to create a 3D conductive interconnecting GNP network dispersed and distributed throughout the polymer matrix so that the external thermal impulse is transferred from the polymer chains to the GNP particles throughout the composite [3, $7,8]$, with negligible phonon scattering.

Fused deposition modelling (FDM) may be employed as a manufacturing process to create highly thermally conductive objects for applications such as flexible nanotechnology. To the best of our knowledge, just a few papers have been published on GNP composites with thermoplastics processed by FDM $[9,10]$. In this short review, we highlight the role of FDM as an innovative process and describe the technical challenges still to be overcome to produce objects with enhanced thermal conductivity (TC) made from composites of GNP and thermoplastics by FDM.

\section{Fused deposition model (FDM)}

The ability to build up complex functional structures in a relatively fast and inexpensive manufacturing process makes additive manufacturing (AM) technology, commonly known as $3 \mathrm{D}$ printing, very attractive to both industry and academia [11-15]. It allows for objects to be built layer-by-layer based on Computer-Aided Design (CAD) software where the objects are modelled as a series of cross-section slices [15]. With the increase demand for light-weight materials having tailored properties suitable for specific applications, there continues to intense interest in thermoplastics processed by AM. While the AM approach has limitations currently with regard large-scale production as well as with high volumes of bulky objects (i.e. long production times and, bespoke expensive printers are required), it is an innovative solution to manufacturing micro-size objects $[16$, 17]. Indeed, the ability to control the size of objects on small-scale dimensions renders AM a valid alternative in application areas such as microelectronics.

To date, polymers such as acrylonitrile butadiene styrene (ABS), poly(lactic acid) (PLA), poly (caprolactone) (PCL), poly (carbonate) (PC) and poly (ether-ether-ketone) (PEEK) among others have been printed by FDM, a specific AM technique usually employed for thermoplastics $[11,18,19]$. In the FDM process with a platform moving in the direction perpendicular to the nozzles $(\mathrm{z}$ direction), a polymer filament is fed to the printer by a roller mechanism and addressed to a liquefier where it is heated above its glass transition temperature $\left(\mathrm{T}_{\mathrm{g}}\right)$. The filament, still solid, acts as a piston pushing the molten polymer through the head print nozzle, which moves in the $x-y$ plane, thus placing the material onto a sliding platform moving in vertical direction $(\mathrm{z})$. When the first layer is completed, the platform slides down allowing a second layer to be placed onto the previous one. The layers adhere to each other as they cool down and the process ends once the entire CAD-programmed structure has been built $[9,20,21]$. The FDM process is represented in Fig. 1 [22].

\section{Requirements for FDM processing}

FDM is basically an extrusion process where the homogeneity of the feedstock material as well as the thermal, mechanical and rheological properties are key features to guarantee the continuity of the printing process and the quality of the final product [10].

\section{(Nano) filler distribution and dispersion}

The printing ability of thermoplastic composites is highly affected by filler dispersion and distribution in the polymer matrix since the filler particles can agglomerate and may clog the print head nozzles causing print jam [10]. This is detrimental for continuity of the process hence the quality of the final product, since any interruption during the printing process produces poor quality products [10]. Therefore, a preliminary mixing step is required for filled thermoplastic polymers to obtain homogeneous composites. By way of example, extrusion is the most common technique used to process thermoplastics and their composites since it is relatively cheap and environment-friendly, thus very attractive to industry. In particular, twin-screw extruders are largely employed as they are effective mixer and have devolatilization capability. Moreover, the ability to modify the shape of the die makes extrusion a flexible process to manufacture material in long filaments with a desired diameter suitable for feeding to FDM printers [23-26].

It is important to highlight that filler dispersion and distribution in the polymer matrix depends on several factors. Besides processing, compatibility between composite components, surface interaction and filler particle geometry are also key factors to consider in trying to achieve homogeneous composites having enhanced chemical, physical and mechanical properties [6, 27, 28] (and references therein).

\section{Thermal properties of the feedstock}

An understanding of the thermal properties of the feedstock composite material is also essential. The material must be heated above the glass transition temperature $\left(\mathrm{T}_{\mathrm{g}}\right)$ of the polymer matrix when extruded through the nozzles and has to remain soft during printing to guarantee a suitable flow, without degrading.

For semi-crystalline polymers, the nozzle temperature is set close to the melting temperature $\mathrm{T}_{\mathrm{m}}$ (glass 


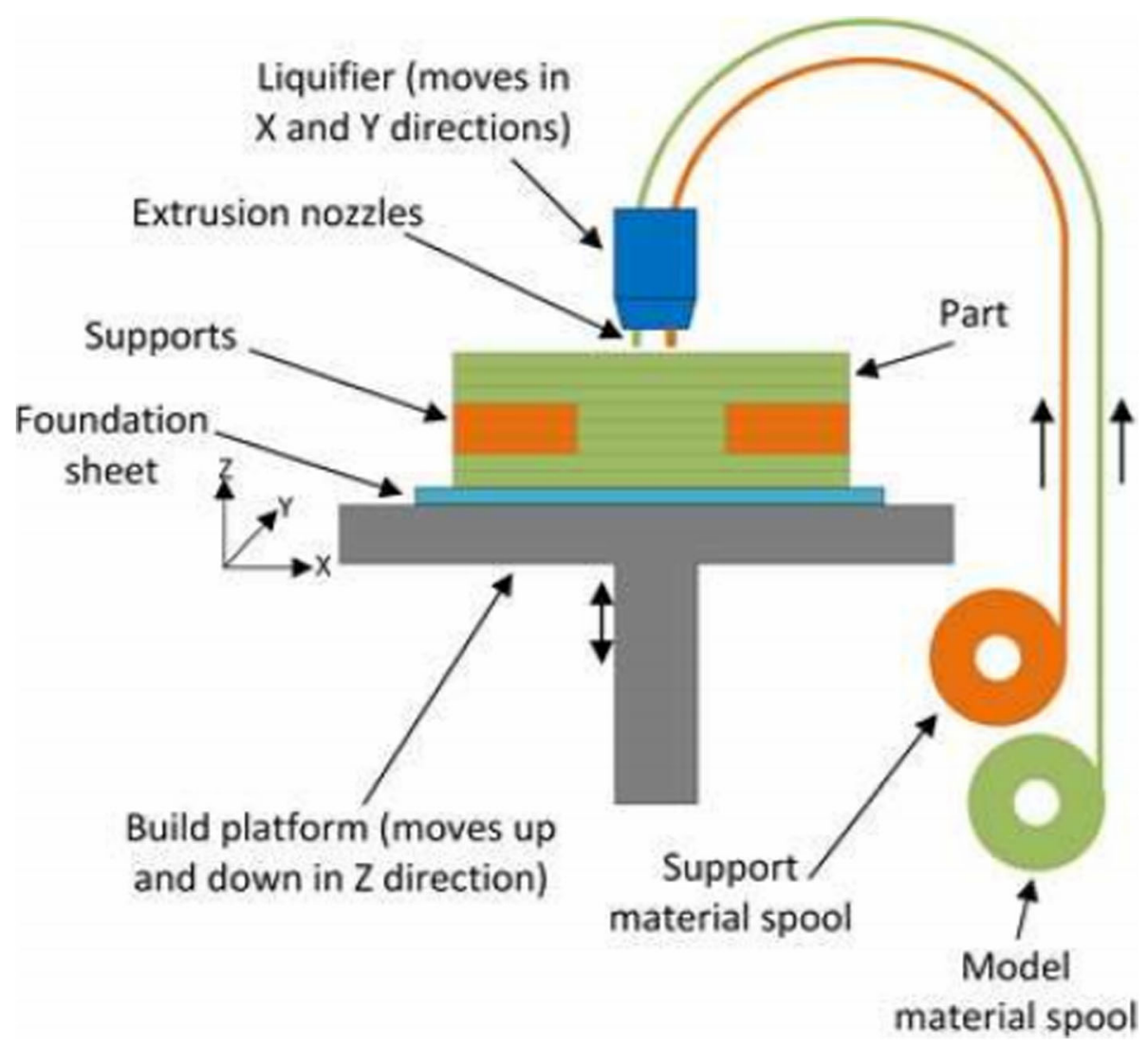

Fig. 1 Schematic diagram showing the important components of a FDM printer [20]

transition temperature $\left(\mathrm{T}_{\mathrm{g}}\right)$, for amorphous polymers), which has not to be high, to prevent severe processing conditions. On the contrary, the degradation temperature $\mathrm{T}_{\text {deg }}$ should be high enough and not fall within the processing temperature range [29]. After printing, the material is cooled down below its crystallization temperature $T_{c}$ ( $T_{g}$ in case of amorphous polymers). It is important that the printed layer is still slightly warm but not totally molten when the next layer is deposited, to allow adhesion between the layers without shape deformation. Experimental evidence has shown that for a successful printing procedure $T_{c}$ and $\mathrm{T}_{\mathrm{m}}$ should differ by about $5-10{ }^{\circ} \mathrm{C}[30]$.

Choosing the right range of temperature could be challenging when it comes to processing composites since the filler may alter the properties of the neat polymer. For instance, GNP may increase both $\mathrm{T}_{\mathrm{g}}$ and $\mathrm{T}_{\mathrm{m}}$ of the polymer [31-33], but not the $T_{\text {deg }}$, thus reducing the range of processing temperatures available. Therefore, the choice of the right polymer matrix having a sufficient high $\mathrm{T}_{\text {deg }}$ must also be considered for the FDM process.

To facilitate the printing procedure, the coefficient of thermal expansion (CTE) of the material has to be low. That is, neither expansion nor contraction has to occur during processing [34]. This is important to guarantee a consistent output when the material is extruded through the nozzle and to achieve a consistent geometry when the material cools down [10].

\section{Rheology}

The rheology of the composite material is critical in controlling FDM processing in terms of product flow consistency and continuity. The viscosity of the material to be printed has to remain as constant as possible during processing, since any fluctuation with temperature and time results in inconsistent flow and the amount of material deposited while printing. Additionally, the melt viscosity has to be low enough, in the range of experimental temperatures to guarantee ease of extrusion through the nozzle head, thus avoiding high pressure at the exit, which may damage the printer. The high flowability is not only essential to effectively extrude the composite material through the nozzle, it also improves the adhesion between the printed layers when they cool down, thus minimizing the number of interfaces (voids generated between two or more touching filaments) [20, 33, 35].

Keeping composite viscosity constant within the range of operation temperatures is not easy due to the viscoelastic properties of the polymer matrix. The viscosity of 
the composite may change by passing from the liquefier to the printing support (different temperatures) as well as by changing the printing speed (deformation speed). When the molten composite is extruded from the nozzles at a defined speed, it passes through high shear stress regions (i.e. walls of the nozzles), which deform the flowing material at a certain rate (shear rate). An increase or decrease of the printing speed alters the shear rate in the material being processed. As the viscosity of non-Newtonian polymers depends on the shear rate, a change in printing speeds may affect the viscosity of the filament being printed [36, 37]. It follows that only a range of optimal viscosities under the operative conditions can be defined, which depends on several parameters such as polymer matrix molecular weight, filler/ polymer interaction and filler concentration [20]. For a given polymer/filler system (i.e. defined polymer molecular weight and polymer/filler thermodynamics), the viscosity increases with filler content and reaches the highest value when a percolated network of filler particles is formed in the matrix. Therefore, the main challenge to obtaining a consistent flow of thermally conductive composite during printing is to achieve percolation at low filler content to keep the viscosity within workable range. Therefore, to enhance TC, a low thermal percolation threshold is necessary in order to process the composite by FDM [38]. Different parameters play a key role in defining the optimal percolation value such as the cost of the functional material, the $3 \mathrm{D}$ printer specifications (e.g. maximum acceptable pressure at the nozzle head nozzle) and the polymer/filler system (i.e. the percolation threshold will change depending on the polymer/filler system).

\section{Mechanical properties}

The mechanical properties of the composites of interest must also be studied before printing. Flexibility is necessary to covert the composite material to filament before being fed in to the FDM printer, but it has to be rigid enough with high mechanical strength to draw it from the feeding system without being plastically deformed. However, brittleness is not desired, since the material cannot break while being pulled from the feeding system. Finally, the material has to be hard enough to prevent surface wearing and tearing [30]. The number of parameters to consider is significant since they depend on the polymer/ filler system and the 3D printer specifications. Moreover, authors usually pay attention to the properties of the printed product and very few papers report the characteristics of the feeding material $[9,21,39]$.

\section{Influence of FDM parameters on thermal conductivity}

The different parameters discussed above affect the TC of the FDM printed object although, it is not easy to compare quantitatively the effect of each parameter on the TC after FDM since the printed samples can be highly anisotropic. Moreover, the effects of voids and printing orientation, feeding and printing rates, nozzle and printing bed temperature also need to consider as they too contribute to the final TC of the printed object.

\section{Void formation and printing direction effects on TC}

The layer-by-layer deposition of the composite material is a key factor in modulating the properties of the final product since different morphologies at the interfaces are created. The molten material assumes a spherical shape when it is extruded from the printer nozzle but, it becomes more elliptical as deposited onto the substrate, thus, creating voids between adjacent printed filaments. The voids break the continuity of the material as insulating walls against thermal flow. However, if the voids are aligned along a specific direction a continuous thermal pathway is realized along the direction perpendicular to that one. For instance, when an external heat stimulus is applied to a 3D system $x-y-z$, a smooth constant thermal conductive flow is realized along the $y$-axis if the voids are all aligned in the $\mathrm{x}-\mathrm{z}$ direction $[9,40]$. It is possible to control the alignment of voids, hence the thermal flow, by properly tuning the printing direction as shown in Fig. 2:

It is evident that when the three layers are all printed along the $y$-axis, the voids are oriented in the $\mathrm{x}-\mathrm{z}$ directions and a continuous pathway for thermal flow is realized along the $y$-axis (Fig. 2 (a) and (b)). If one of the three layers, the middle one in Fig. 2(c) is not aligned in the same direction, then that specific layer becomes a discontinuity to the heat flow and thermal conduction along y-axis is lower, see Fig. 2 (d). In particular, for the middle layer the voids are aligned along the y-axis and act as insulating "bubbles" on the thermal flow along that direction. Shemelys et al. [41] prepared both composites of ABS with graphite and with CNTs by extrusion and post-processed them by FDM. The wide distribution of the voids created upon printing resulted in poor thermal conduction of the final printed composite (TC method: hot-disk). Yunchao et al. [40] were able to improve the TC of polyamide 6 (PA6) with inclusion of $50 \mathrm{wt} \%$ graphite from $0.5 \mathrm{~W} / \mathrm{mK}$ to $6 \mathrm{~W} / \mathrm{mK}$ when printing the layers along the same direction (TC method: hot disk).

It must be highlighted that two conditions are necessary to achieve a thermal pathway along the printing direction ( $y$ in the example above). Besides the alignment of voids along the appropriate directions $(\mathrm{x}$ and $\mathrm{z}$ in the example above), filler particle alignment along the printing direction is also essential. Indeed, no thermal flow can be realised along a given axis if the conductive particles are not aligned along that axis and form an 
(a)

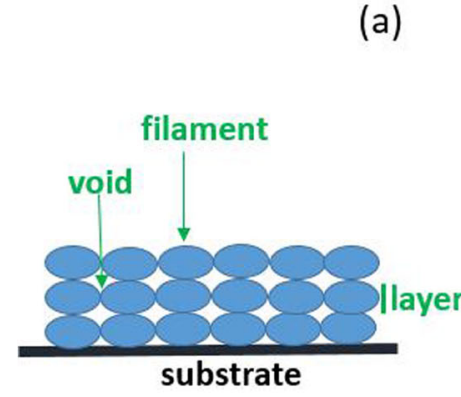

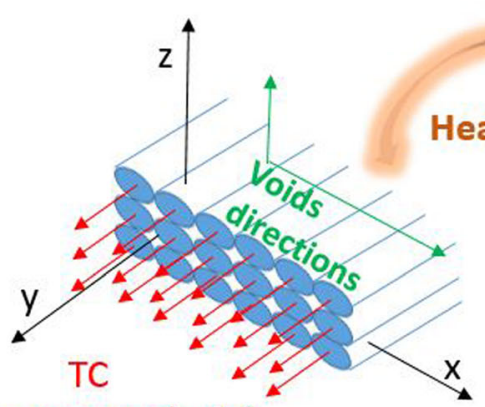

TC

(b)

Heat stimulus

(c)

(3 layers contribute)

(d)

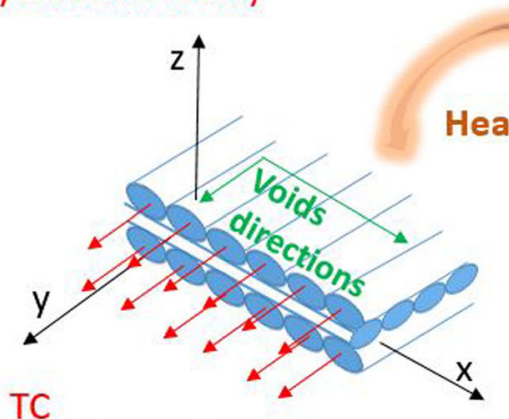

Heat stimulus

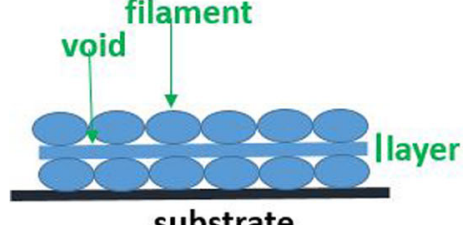

TC

(2 layers contribute)

Fig. 2 Schematic diagram illustrating the effect of voids and printing direction on TC. $\mathbf{a}, \mathbf{b}$ filaments printed with the same orientation generate voids perpendicularly arranged ( $x$ - $z$ directions), with respect to the thermal conduction direction (y-direction) thus maximizing TC along the conductive axis (y-axis) and $\mathbf{c}, \mathbf{d}$, filaments printed in different orientations generate voids along the thermal conduction direction, thus reducing TC along the conductive axis (y-axis)

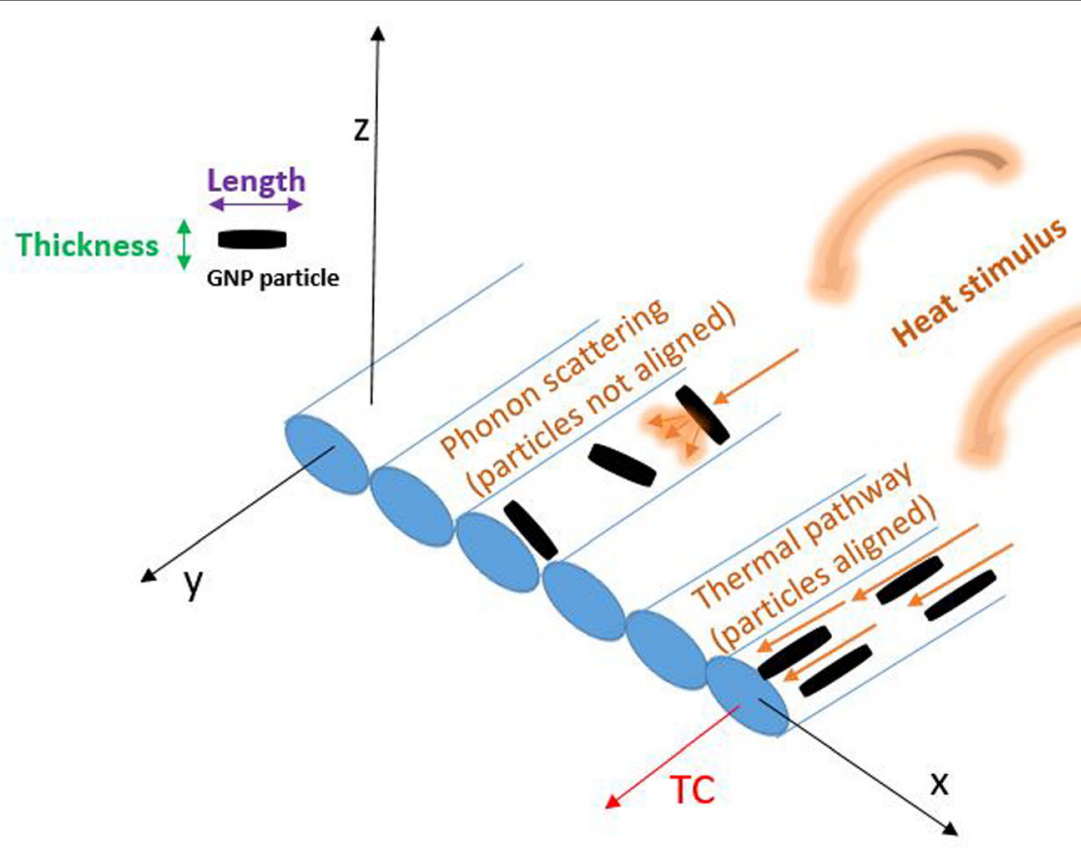

Fig. 3 Schematic illustration of thermal conduction within printed filaments of a composite of GNP and a polymer. When the GNPs are aligned along the conductive axis (y-axis) TC is detected 
interconnected 3D network within the matrix (percolated structure) with negligible phonon scattering [6] (and references therein). When dealing with 2D materials like GNPs, defining the concept of particle alignment is crucial to understanding the thermal conductivity of their composites. Thermal conduction is maximum along GNP particle length and minimum along its thickness due to phonon scattering, which decreases with the reduction in the number of layers (thickness) [42-46]. It is essential for GNP composites to be conductive along a specific direction such that the GNP particles are arranged with the platelets facing along that direction [47]. Figure 3 shows a schematic of GNP particle alignment in a 3D printed layer:

When the GNP particles are aligned in a way that their length lies along the y-axis, a thermal pathway is realized, given there is a greater chance the particles are touching then TC is detected along the $\mathrm{y}$-axis when a heat stimulus is applied. In contrast, if GNP particles are not properly aligned along the y-axis, phonon scattering dominates upon application of heat and no TC can be detected in they-axis direction [40].

The alignment of filler particles in the printing direction can be achieved by orienting the polymer chains $[48,49]$. Polymer chains stretch as they are forced to pass through the printer head nozzle acting as an orienting pulling force onto filler particles and causing their alignment in the printing direction $[9,50]$. By way of example, Zhu et al. [51] prepared composites of PA12 with GNP (6wt\%) with a co-rotating twin screw extruder (screw diameter $=20 \mathrm{~mm}$; L/D ratio $=40$ ) and postprocessed them by compression moulding and FDM. The FDM samples showed higher through-in-plane TC than the compression moulded ones $(1.2 \mathrm{~W} / \mathrm{mK}$ and 0.2 $\mathrm{W} / \mathrm{mK}$ respectively, TC method: laser flash) due to the alignment of GNP along the printing direction. Liao et al. [52] prepared composites of PA12 with carbon fibre $(10 \mathrm{wt} \%)$ with a co-rotating twin screw extruder (screw diameter $=35 \mathrm{~mm}, \mathrm{~L} / \mathrm{D}=28$ ) and fed the filament to the FDM machine. The through-in-plane TC of the final sample improved from $0.2 \mathrm{~W} / \mathrm{mK}$ to $0.8 \mathrm{~W} / \mathrm{mK}$ when the carbon fibres were arranged in a way to create an oriented path, thus facilitating thermal flow. However, the overall $\mathrm{TC}$ value was low probably due to the voids in the TC direction (TC method: laser flash). In some instances, the nature and the shape of the filler particles prevents their alignment, as reported by Dorigato et al. [53], who prepared composites of ABS with CNTs (6 wt\%) by using a twin screw extruder (screw diameter $=16 \mathrm{~mm}, \mathrm{~L} / \mathrm{D}=25$ ), before feeding the filaments to a FDM. The final composites had a low thermal conductivity $(c a 0.25 \mathrm{~W} / \mathrm{mK})$ probably due to the unfavourable orientation of the CNTs in ABS after printing (TC method: laser flash).
An interconnected system of filler particles (3D network) is needed to create a conductive path. Lebedev et al. [38] prepared composites of PLA with graphite and CNTs using a mixer having counter-rotating blades before post-processing by FDM. They were able to obtain a $\mathrm{TC}$ of $4 \mathrm{~W} / \mathrm{mK}$ for composites with $30 \mathrm{wt} \%$ graphite and 1 wt\% CNTs (TC method: hot wire). The authors asserted that the CNT bridged the graphite particles, thus creating a three-dimensional hybrid network, which ultimately improved the TC of the final composites. Singh et al. [54]improved the TC of ABS with exfoliated graphite ( $22 \mathrm{wt} \%$ ) by adding the filler to a slurry of ABS and acetone. The mixture was dried and the resulting composites (recovered as a lump of materials) was broken in to smaller pieces before extrusion. The extruded filament was printed and the final material had a $\mathrm{TC}$ of $17.60 \mathrm{~W} / \mathrm{mK}$ (TC method: hot disk). The corresponding composites prepared by direct mixing of the same graphite with ABS had a TC of $4.65 \mathrm{~W} / \mathrm{mK}$. It appears that the sludge of ABS and acetone somehow better facilitated the formation of a conductive graphite network.

\section{Effect of printing and feeding rates on TC}

The printing rate (speed at which a filament is deposited) and feeding rates (speed at which the material is loaded into the nozzle) [20] influence the thermal conduction of the final composite in terms of filament adhesion when printing. Layers not properly adhered to each other create large interfaces (voids) which lead to phonon scattering, hence low thermal conduction $[40,41]$. Overall, the higher the printing and feeding rates, the better the adhesion, hence the smaller the interfaces between the printed layers. In fact, high printing rate assures that the temperature of the extruded material is closer to the $T_{g}$ ( $T_{m}$ for semi-crystalline materials) than the one printed using a slower printing rate, as the former results in better interactions and bonding among adjacent filaments $[9,55]$. Likewise, for a given printing rate (feeding rate), high feeding rate (low printing rate) allows printing of thicker filaments, which are able to adhere better than thinner ones, even though there is a loss in geometrical resolution $[9,56]$.

\section{Effect of nozzle and cooling bed temperature on TC}

Nozzle temperature and the building platform temperature (cooling bed) are crucial in determining the quality of the final product since they influence the physical properties of the printing materials in terms of viscosity and crystallization $[10,20,21]$. Overall, a constant flow through the nozzle due to an appropriate viscosity guarantees a uniform material with a low concentration of defects, both on the microscopic (i.e. voids, polymer chain adhesion) and 
macroscopic (i.e. constant shapes and regular amounts of deposited material) level [56]. This reduces the probability of phonon scattering hence better thermal conduction is achieved [40]. Indeed, as explained before, the presence of defects generate structural discontinuities inside of the material, thus, disrupting the phonon path, which ultimately causes phonon scattering, hence low thermal conduction [6] (and references therein). Additionally, crystallization realized under controlled conditions produces more highly crystalline materials, known to dissipate heat more efficiently [39, 57].

The nozzle temperature has to be set in a way to ensure that the composite matrix material is fully molten since the presence of un-melted polymer leads to uneven temperatures inside the nozzle, which may cause a reduction in crystallinity upon material solidification [39]. Indeed, polymer chains will not behave uniformly when they are not subject to the same temperature regime during printing, since they will experience different crystallization rates when cooling. Some chains may crystallize from very high temperatures, while others crystallize from lower temperatures, leading to a product with non-homogeneous properties [21]. Furthermore, the nozzle temperature has to guarantee an easy flow of the material as well as having a viscosity to keep shape after printing [30].

The bed temperature mainly influences the crystallization process. When the bed temperature is much lower than the nozzle temperature, the printed material will experience non-isothermal crystallization, which may reduce polymer crystallinity. By contrast, if the cooling temperature is closer to the nozzle temperature, the printing material will experience a quasi-isothermal crystallization, which ultimately may produce a highly crystalline material [21].

Figure 4 shows a schematic diagram of the optimal nozzle/ and bed temperature ranges for semi-crystalline polymers, constructed from experimental evidence reported in literature.

\section{Summary of composites of polymers and carbonaceous additives prepared by FDM}

Table 1 lists the main properties of 3D printed (FDM) of composites of polymers with carbonaceous additives reported in literature at the time of writing.

As evident from Table 1, composites of polymers and GNP/graphene printed by FDM are seldom reported and of those only a few authors focus their research on studying TC. Likewise, the electrical properties of these FDM printed composites are also rarely analysed. Gnanasekaran et al. [39], Wei et al. [10] and Yu et al. [67], prepared composites of a polymer and graphene by FDM and obtained EC values not higher than $1 \mathrm{~S} / \mathrm{m}$. The aggregation of graphene during printing caused inhomogeneities, poor (nano) filler dispersion and distribution, which ultimately resulted in poorly performing FDM printed composites. Gnanasekaran et al. [39] also studied the properties of composite of PBT and MWCNTs and the final printed composites displayed an increase in EC up to $10 \mathrm{~S} / \mathrm{m}$. The author assigned the improved performance to the alignment of the MWCNTs upon printing.

Reports on CF based composites prepared by FDM are much more common and the natural alignment of $\mathrm{CF}$ along the printing filaments confers the final products with exceptional mechanical properties (see Table 1). However, GNP is a valid alternative to manufacturing functional materials by FDM as proven by Dingchun et al. [51], who prepare composites of PA12 and GNP (6wt\%) showing similar mechanical properties to the composites of PA12 with CF (6 wt\%) prepared by Liao et. al. [52] Indeed, the concurrent alignment of the voids and GNP particles in the tensile direction resulted in an increase in Young's modulus of ca 50\% with respect to the neat PA12 and an increase of $7 \%$ compared to the

\section{Temperature settings for semi-crystalline materials}

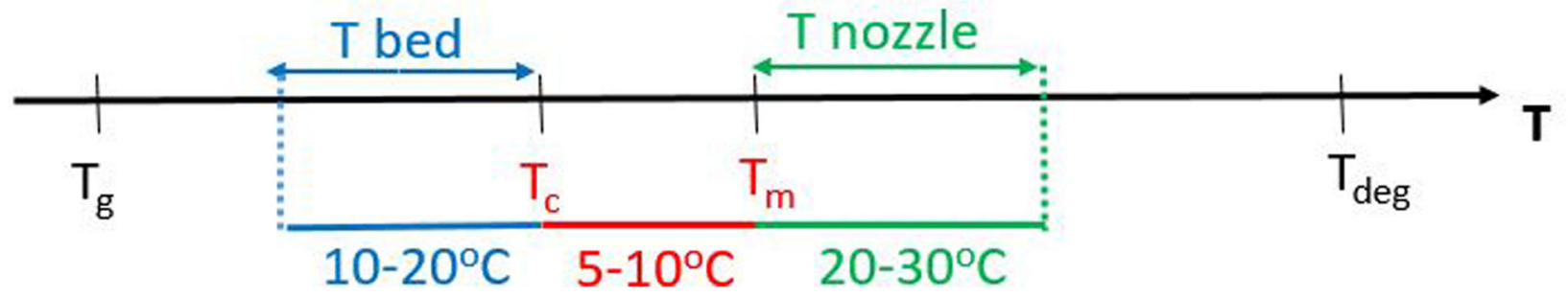

Fig. 4 FDM temperature settings for semi-crystalline polymers and their composites 
Table 1 Main properties of composites of polymers with carbonaceous additives prepared by FDM as reported in literature. ${ }^{a}$ CF: carbon fibre, ${ }^{\mathrm{b}}$ CNT/MWCNTs: carbon nanotube/multi-walled carbon nanotubes, ${ }^{\mathrm{C}} \mathrm{CB}$ : carbon black, ${ }^{\mathrm{d}}$ PEl: Poly(ether imide)

\begin{tabular}{|c|c|c|c|}
\hline Matrix & Filler & Properties & References \\
\hline \multicolumn{4}{|c|}{ Thermal properties } \\
\hline ABS & ${ }^{\mathrm{a}} \mathrm{CF}(13 \mathrm{wt} \%)$ & $\mathrm{CTE}\left(\mu \mathrm{m} / \mathrm{m}^{\circ} \mathrm{C}\right): 9.85 ; \mathrm{TC}(\mathrm{W} / \mathrm{mK}): 0.4$ (in-plane) & {$[58]$} \\
\hline PLA & $\begin{array}{l}{ }^{\mathrm{b}} \text { Graphite }(30 \text { wt } \%) / C N T(1 \\
\text { wt\%) }\end{array}$ & $\mathrm{TC}(\mathrm{W} / \mathrm{mK}): 5$ & {$[38]$} \\
\hline PLA & Graphene & $\Delta \mathrm{T}\left({ }^{\circ} \mathrm{C}\right): 0.5$; (Voltage applied: $10 \mathrm{~V}$, time: $300 \mathrm{~s}$ ) & [59] \\
\hline PA6 & Graphite (50 wt\%) & TC(W/mK):5.5 (through-plane) & [40] \\
\hline ABS & CNT(8 wt\%) & $\Delta \mathrm{T}\left({ }^{\circ} \mathrm{C}\right): 250 ;$ (Voltage applied:24 V,10s) & [53] \\
\hline ABS & Graphite (4.3vol\%) CF(1.7vol\%) & $\begin{array}{l}\text { TC(W/mK):0.4 (in-plane) } \\
\text { TC(W/mK):0.2 (in-plane) }\end{array}$ & [41] \\
\hline ABS & Graphite (21.7w\%) & $\mathrm{TC}(\mathrm{W} / \mathrm{mK}): 17.60$ & [54] \\
\hline PA12 & GNP(10 wt\%) & $\mathrm{TC}(\mathrm{W} / \mathrm{mK}): 1.2$ & [51] \\
\hline PA12 & CF(10 wt\%) & $\mathrm{TC}(\mathrm{W} / \mathrm{mK}): 0.8$ & {$[52]$} \\
\hline \multicolumn{4}{|c|}{ Electrical properties } \\
\hline ABS & CNT (10 wt\%) & $\mathrm{EC}(\mathrm{S} / \mathrm{cm}): 3.3 \times 10^{-6}$ & {$[60]$} \\
\hline PLA & ${ }^{\mathrm{b}} \mathrm{MWCNT}(10 \mathrm{wt} \%)$ & $\mathrm{EC}(\mathrm{S} / \mathrm{cm}): 6 \times 10^{3}$ & [61] \\
\hline $\mathrm{PCL}$ & ${ }^{\mathrm{C}} \mathrm{CB}(15 \mathrm{wt} \%)$ & Electrical resistance $(\mathrm{k} \Omega)$ : 19 (60s) & {$[62]$} \\
\hline Epoxy & CNF(4 wt\%) & Surface resistivity ( $\Omega / \mathrm{sq}$.):1000; Volume resistivity $(\Omega \mathrm{cm}): 1000$ & [63] \\
\hline TPU & MWCNT (3 wt\%) & Relative resistance (R/R0):6 (tensile strain: 50\%, 20 cycles) & [64] \\
\hline PLA & CF(20 wt\%) & $\begin{array}{l}\text { Relative resistance }(\mathrm{R} / \mathrm{RO} 0): 3.5 \text { (tensile strain:1.7\%, stress: } 20 \mathrm{MPa} \text { ) } \\
\text { Relative resistance }(\mathrm{R} / \mathrm{RO}): 1.2 \text { (tensile strain:5\%, Force }(\mathrm{N}): 100)\end{array}$ & {$[65]$} \\
\hline ABS & CNT(8 wt\%) & Electrical resistivity $(\Omega \mathrm{cm}): 1$ & [53] \\
\hline${ }^{d}$ PEI & MWCNT & Resistance $(\Omega): 15.37$ (220 s under cyclical mechanical loading) & [66] \\
\hline \multirow[t]{2}{*}{ PBT } & CNT(0.04vol\%) & $\mathrm{EC}(\mathrm{S} / \mathrm{m}): 10$ & [39] \\
\hline & Graphene (0.09vol\%) & $\mathrm{EC}(\mathrm{S} / \mathrm{m}): 1$ & \\
\hline ABS & Graphene (8 wt\%) & $\mathrm{EC}(\mathrm{S} / \mathrm{m}): 0.01$ & [10] \\
\hline \multirow[t]{2}{*}{ PLA } & Graphene (8 wt\%) & $\mathrm{EC}(\mathrm{S} / \mathrm{m}): 1$ & [67] \\
\hline & CNT(8 wt\%) & $\mathrm{EC}(\mathrm{S} / \mathrm{m}): 1$ & \\
\hline \multirow[t]{2}{*}{ ABS } & CB(1.32vol\%) & $\mathrm{EC}(\mathrm{S} / \mathrm{cm}): 10^{-8}$ & {$[68]$} \\
\hline & CNT(1.38vol\%) & $\mathrm{EC}(\mathrm{S} / \mathrm{cm}): 0.01$ & \\
\hline ABS & $\mathrm{CB}(15 \mathrm{wt} \%)$ & Resistivity ( $\Omega \cdot m): 120 @ 1 \mathrm{~Hz}$ & \\
\hline PLA & GNP(8 wt\%) & Capacitance ( $\mu \mathrm{F}): 28 @ 0.5 \mu \mathrm{A}$ & {$[69]$} \\
\hline PMMA & GNP (10 wt\%) & $\mathrm{EC}(\mathrm{S} / \mathrm{cm}): 14.2$ & [70] \\
\hline \multicolumn{4}{|c|}{ Mechanical properties } \\
\hline ABS & MWCNT (10 wt\%) & E (MPa): 1600; $\sigma(\mathrm{MPa}): 56 ; \varepsilon(\%): 5$ & {$[60]$} \\
\hline ABS & CNT $(3 w t \%)+C F$ & E (MPa): 3400 & [71] \\
\hline PLA & CF (6.6 vol\%) & E (MPa): 20000; $\sigma(\mathrm{MPa}): 180 ; \varepsilon(\%): 1$ & [72] \\
\hline ABS & CF (10 wt $\%)$ & $\mathrm{E}(\mathrm{MPa}): 7900 ; \sigma(\mathrm{MPa}): 37.4 ; \varepsilon(\%): 5$ & [73] \\
\hline PLA & Graphene (0.5 wt\%) & E (MPa):2000; $\sigma(\mathrm{MPa}): 40 ; \varepsilon(\%): 25$ & [74] \\
\hline PLA & MWCNT (0.5 wt\%) & E (MPa):2500; $\sigma(\mathrm{MPa}): 40 ; \varepsilon(\%): 25$ & [74] \\
\hline ABS & CF(7.5 wt\%) & E (MPa):2500; $\sigma(\mathrm{MPa}): 25 ;$ Ductility (\%): 3 & [75] \\
\hline PLA & CF (13 wt\%) & E increase (\%):350; $\sigma(\mathrm{MPa}): 200$ & {$[76]$} \\
\hline ABS & CF (30 wt $\%)$ & E (MPa):13000; $\sigma(\mathrm{MPa}): 60$ & [77] \\
\hline \multirow[t]{2}{*}{ Epoxy } & CF & 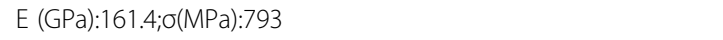 & [78] \\
\hline & & Flexural modulus (GPa):144; Flexural strength (MPa):202 & \\
\hline
\end{tabular}


Table 1 Main properties of composites of polymers with carbonaceous additives prepared by FDM as reported in literature. ${ }^{a}$ CF: carbon fibre, ${ }^{\mathrm{b}}$ CNT/MWCNTs: carbon nanotube/multi-walled carbon nanotubes, ${ }^{\mathrm{C}} \mathrm{CB}$ : carbon black, ${ }^{\mathrm{d}}$ PEl: Poly(ether imide) (Continued)

\begin{tabular}{|c|c|c|c|}
\hline Matrix & Filler & Properties & References \\
\hline PLA & CF & $\begin{array}{l}\text { Flexural modulus (GPa): 10; Flexural strength }(\mathrm{MPa}): 180\left(\mathrm{~T}_{\text {liquefier }}=210^{\circ} \mathrm{C} \text {, layer thickness }=0.5\right. \\
\mathrm{mm})\end{array}$ & [20] \\
\hline PLA & Modified CF & Flexural modulus (MPa):91; Flexural strength (MPa):156 & [79] \\
\hline Epoxy & $\mathrm{SiC} / \mathrm{C}(31 \mathrm{vol} \%)$ & $\mathrm{E}(\mathrm{GPa}): 24.5 ; \sigma(\mathrm{MPa}): 66.2$ & {$[80]$} \\
\hline Nylon & CF (34.5vol\%) & $\sigma(\mathrm{MPa}): 500 ; \varepsilon(\%): 1.7$ (6CF layers) & [81] \\
\hline ABS & CF(1.4vol\%) & $\sigma(\mathrm{kN}): 1.5 ;$ Stroke $(\mathrm{mm}): 4.5$ & {$[82]$} \\
\hline TPU & MWCNT(3 wt\%) & $\sigma(\mathrm{MPa}): 3 ; \varepsilon(\%): 50$ (20 cycles, linear biaxial sensor) & [64] \\
\hline ABS & CF(13 wt\%) & $\mathrm{E}(\mathrm{MPa}): 71 ; \sigma(\mathrm{MPa}): 7$ & {$[58]$} \\
\hline \multirow[t]{2}{*}{ PLA } & CF(20wt\%) & $\sigma(\mathrm{MPa}): 32.5 ; \varepsilon(\%): 1.7$ & [65] \\
\hline & & Flexural strength (MPa):68.2; Flexural strain(\%):5 & \\
\hline PEl & CNT & $\sigma(\mathrm{MPa}): 120 ; \varepsilon(\%): 5$ & [66] \\
\hline PLA & Graphene(8 wt\%) & $\sigma(\mathrm{MPa}): 60 ; \varepsilon(\%): 4$ & {$[50]$} \\
\hline ABS & Graphene (8 wt\%) & $\mathrm{E}(\mathrm{MPa}): 3500 ; \sigma(\mathrm{MPa}): 2700$ & [9] \\
\hline ABS & CF(18wt\%) & $\sigma(\mathrm{MPa}): 58.6$ & [30] \\
\hline \multirow[t]{2}{*}{ PLA } & Recycled CF & $\mathrm{E}(\mathrm{GPa}): 20 ; \sigma(\mathrm{MPa}): 250$ & [83] \\
\hline & & Flexural modulus (GPa):13;Flexural strength (MPa):250 & \\
\hline ABS & CNT(8 wt\%) & $\sigma(\mathrm{MPa}): 37 ; \varepsilon(\%): 7$ & [53] \\
\hline \multirow[t]{2}{*}{ ABS } & Graphite(4.3vol\%) & $\sigma(\mathrm{MPa}): 37.55 ; \varepsilon(\%): 6$ & [41] \\
\hline & CF(1.7vol\%) & $\sigma(\mathrm{MPa}): 35.73 ; \varepsilon(\%): 10$ & \\
\hline PA12 & GNP(6 wt\%) & E (MPa):2252; $\sigma(\mathrm{MPa}): 41 ; \varepsilon(\%): 12$ & [51] \\
\hline PA12 & CF(6 wt\%) & $\mathrm{E}(\mathrm{MPa}): 2700 ; \sigma(\mathrm{MPa}): 80 ; \varepsilon(\%): 5$ & {$[52]$} \\
\hline \multirow[t]{3}{*}{ PLA } & Graphene & E (GPa):4; Nanohardness (MPa):146 & [84] \\
\hline & & Wear volume loss $\left(\mathrm{mm}^{3}\right): 3.5(20 \mathrm{~N}, 30 \mathrm{~s})$ & \\
\hline & & Creep displacement $(\mu \mathrm{m}): 0.3(25 \mathrm{mN}, 1 \mathrm{~s})$ & \\
\hline \multirow[t]{3}{*}{ PLA } & Graphene (2 wt\%) & $\mathrm{E}(\mathrm{MPa}): 900 ; \sigma(\mathrm{MPa}): 60$ & [67] \\
\hline & & Flexural modulus (MPa):3070; Flexural strength (MPa):94.2 & \\
\hline & CNT (2 wt\%) & Flexural modulus (MPa):2620; Flexural strength (MPa):82 & \\
\hline PA6 & CF(25vol\%) & $\mathrm{E}(\mathrm{GPa}): 53$ & [85] \\
\hline PEEK & MWCNT(5vol\%) & Ultimate strength (MPa): 105 & {$[86]$} \\
\hline PA6 & CF(40vol\%) & $\mathrm{E}(\mathrm{GPa}): 68 \pm 6 ; \sigma(\mathrm{MPa}): 700 \pm 70$ & [87] \\
\hline $\begin{array}{l}\text { TPU/ } \\
\text { PLA }\end{array}$ & GO(5 wt $\%)$ & $\mathrm{E}(\mathrm{MPa}): 55$ & {$[88]$} \\
\hline PEEK & CF(28vol\%)/GNP(5vol\%) & $\mathrm{E}(\mathrm{GPa}): 7$ & [89] \\
\hline EVA & Graphite (40 wt\%) & Compressive strength (MPa): 30; Hardness (Shore D): 28 & [90] \\
\hline PLA & GNP(10 wt\%) & $\mathrm{E}: 2.4 \mathrm{GPa} ; \sigma: 40 \mathrm{MPa}$ & [91] \\
\hline $\mathrm{ABS}$ & MWCNT(8 wt\%) & $\mathrm{E}(\mathrm{MPa}): 2150 \pm 80 ; \sigma(\mathrm{MPa}): 46.9 \pm 0.9 ; \varepsilon(\%): 4.0 \pm 0.7$ & [92] \\
\hline PLA & GNP(12 wt\%) & $E(G P a): 3.5 \pm 0.048 \pm 0.257$ & [93] \\
\hline
\end{tabular}

correspondent compression moulded sample. The value of $\mathrm{E}$ reported (2252 MPa) is close to that obtained by Liao et. al [52] (2700 MPa). In some instances, a combination of CF and GNP can improve the mechanical properties of the matrix they are added to. Indeed, Papageorgiou at al [89]. increased the value of E for PEEK by adding GNP (5 vol\%) and CF (28vol\%) and the authors proposed that the high aspect ratio of both CF and GNP limited the mobility of PEEK chains, thus increasing the stiffness. GNP has also been added to biocompatible polymers such as PLA and printed by FDM. By way of example, Prashantha et al. [91] improved the mechanical 
properties of PLA by preparing composites with GNP (10 wt\%) by FDM and the authors proposed that this improvement was derived from the compatibility between GNP and PLA, which in turn facilitated GNP dispersion in the matrix. Composites of PLA with GNP were also used to prototype capacitors manufactured by FDM. Foster et al. [69] added GNP (8wt\%) to PLA and manufactured a pseudo-capacitor by FDM which had a capacitance of $c a 28 \mu \mathrm{F}$ (under a current of $0.5 \mu \mathrm{A}$ ). The authors asserted that even though the value obtained was not as competitive as current capacitors on the market, FDM presents an alternative route to prepare such electronic devices.

Other authors have explored the viability of FDM to print composites of polymer blends and modified GNP. Chen et al. [88] prepared composites of TPU/PLA with GO (5 wt\%) and they obtained improvement mechanical properties which the authors ascribed to reduced porosity of the printed part achieved by modulating the printing direction of the filaments.

\section{Conclusions}

FDM may be employed to print composites of thermoplastics with GNP and other carbonaceous fillers (e.g. MWCNTs, CF), in order to obtain objects with improved TC and potentially other properties. To the best of our knowledge, just a few papers have been published on FDM of composites of polymers and graphene(s), yet the concept is routinely proposed as a route to manufacture products that not only could have enhanced properties but also have functional properties in different directions in the same product, e.g. in battery applications. The technical challenges to successfully 3D print filled polymers by FDM still remain and, there is an immediate need for both innovative solutions and systematic studies that address these challenges.

In this mini-review, we have discussed the key parameters that must be considered to successfully produce a product from GNP filled polymers by FDM, with the target of achieving enhanced TC. Ostensibly, FDM is an extrusion process where the homogeneity of the feedstock material and the thermal, mechanical and rheological properties of the composite material are key to ensuring continuity of the printing process and the quality and functionality of the final product.

Furthermore, there are a number of FDM processing parameters that must be considered and which ultimately will determine the TC value obtained, including the presence of voids, orientation effects, feeding and printing rates, nozzle and printing bed temperatures. The voids break the continuity of the printing material acting as insulating walls against thermal flow. However, if the voids are aligned in a specific direction a continuous thermal pathway is realized in the perpendicular direction. The printing and feeding rates influence the thermal conduction of the final composite in terms of filament adhesion during printing the material. Layers not properly adhered to each other create large interfaces which lead to phonon scattering, hence low thermal conduction. Overall, the higher the printing and feeding rates, the better the adhesion, hence the smaller the interfaces between printed layers. Nozzle temperature and cooling bed temperature are crucial in determining the quality of the final product since they influence the physical properties (i.e. melt viscosity and crystallization of the composite material. When the composite matrix is a semi-crystalline polymer, the nozzle temperature should be set close to the $\mathrm{T}_{\mathrm{m}}$ (up to $c a$ $30{ }^{\circ} \mathrm{C}$ higher), while the bed temperature should be set ca $10-20{ }^{\circ} \mathrm{C}$ below the $\mathrm{T}_{\mathrm{c}}$.

While the published literature on FDM of carbon fibre based composites is more common and to a lesser extent on CNTs, FDM of GNP based composites is a viable alternative to preparing bespoke complex products having functional properties. Indeed, the alignment of GNP in the printing direction will lead to products with combinations of remarkable properties and in different directions if required, e.g. thermal and mechanical properties. However, if the hype is to be overcome a more fundamental understanding of processingstructure-property relationships is required if GNP filled polymers can be printed by FDM in to useful products.

\section{Abbreviations}

GNP: Graphene nanoplatelets; FDM: Fused deposition model; TC: Thermal conductivity; AM: Additive manufacturing; CAD: Computer-Aided Design; ABS: Acrylonitrile butadiene styrene; PLA: Poly(lactic acid);

CL: Poly(caprolactone); PC: Poly(carbonate); PEEK: Poly(ether-ether-ketone); $\mathrm{T}_{\mathrm{g}}$ : Glass transition temperature; $T_{\text {deg: }}$ : Degradation temperature;

$\mathrm{T}_{c}$ : Crystallization temperature; $\mathrm{T}_{\mathrm{m}}$ : Melting temperature; CTE: Coefficient of thermal expansion; MFI: Melt flow index; PA6/PA12: Poly(amide) 6/12; TPU: Thermoplastic polyurethane; PEl: Poly(etherimide); PBT: Poly(butyl terephthalate); CNT: Carbon nanotube; MWCNT: Multiwall-carbon nanotube; CB: Carbon black; SiC: Silicon carbide; GO: Graphene Oxide

\section{Acknowledgements}

VG thanks the EPSRC (EP/L016389/1) and Thomas Swan Ltd. for funding an EngD.

\section{Authors' contributions}

TMCN conceived the topic; TMCN and VG drafted the article; TMCN, VG and $\mathrm{CW}$ reviewed and corrected the article. The authors read and approved the final manuscript.

\section{Funding}

This work was funded by the EPSRC (Grant No.: EP/L016389/1) and Thomas Swan Ltd., UK.

Availability of data and materials

All data generated or analyzed during this study are included in this published article.

Competing interests

The authors declare that they have no competing interests. 
Received: 30 October 2019 Accepted: 19 January 2020

Published online: 19 May 2020

\section{References}

1. D. Akinwande, N. Petrone, J. Hone, Nat. Commun. 5 (2014)

2. H.Y. Chang, S.X. Yang, J.H. Lee, et al., ACS Nano 7, 6 (2013)

3. S. Das, R. Gulotty, A.V. Sumant, et al., Nano Lett. 14, 5 (2014)

4. G.H. Lee, Y.J. Yu, X. Cui, et al., ACS Nano 7, 9 (2013)

5. J. Lee, T.J. Ha, H.F. Li, et al., ACS Nano 7, 9 (2013)

6. V. Guerra, C.Y. Wan, T. McNally, Prog. Mater. Sci. 100 (2019)

7. W. Zhou, S. Qi, H. Li, et al., Thermochim. Acta 452, 1 (2007)

8. S.G. Mosanenzadeh, H.E. Naguib, Compos. Part B-Eng. 85 (2016)

9. S. Dul, L. Fambri, A. Pegoretti, Composites Part A-Appl. Sci. Manufacturing 85 (2016)

10. X.J. Wei, D. Li, W. Jiang, et al., Sci. Rep. 5 (2015)

11. R.D. Farahani, M. Dube, D. Therriault, Adv. Mater. 28, 28 (2016)

12. S. Shaffer, K.J. Yang, J. Vargas, et al., Polymer 55, 23 (2014)

13. S.H. Masood, W.Q. Song, Mater. Des. 25, 7 (2004)

14. M. Nikzad, S.H. Masood, I. Sbarski, Mater. Des. 32, 6 (2011)

15. A. de Leon, Q.Y. Chen, N.B. Palaganas, et al., React. Funct. Polym. 103 (2016)

16. S.Y. Wu, C. Yang, W.Y. Hsu, et al., Microsyst. Nanoengineering 1 (2015)

17. R.D. Sochol, E. Sweet, C.C. Glick, et al., Microelectron. Eng. 189 (2018)

18. K. Fu, Y.G. Yao, J.Q. Dai, et al., Adv. Mater. 29, 9 (2017)

19. H. Ota, S. Emaminejad, Y.J. Gao, et al., Adv. Mat. Technol. 1, 1 (2016)

20. X.Y. Tian, T.F. Liu, C.C. Yang, et al., Composites Part A-Appl. Sci. Manufacturing 88 (2016)

21. C. Yang, X. Tian, D. Li, et al., J. Mater. Process. Technol. 248 (2017)

22. A.W. Gebisa, H.G. Lemu, Materials 11, 4 (2018)

23. S. Hansch, R. Socher, D. Pospiech, et al., Compos. Sci. Technol. 72, 14 (2012)

24. K.B. Nie, X.J. Wang, L. Xu, et al., Mater. Des. 36 (2012)

25. T. Sakai, Polimery 58, 11-12 (2013)

26. T. Villmow, P. Potschke, S. Pegel, et al., Polymer 49, 16 (2008)

27. A.K. Naskar, J.K. Keum, R.G. Boeman, Nat. Nanotechnol. 11, 12 (2016)

28. A.J. McNamara, Y. Joshi, Z.M.M. Zhang, Int. J. Therm. Sci. 62 (2012)

29. E. Bassoli, A. Gatto, L. Iuliano, et al., Rapid Prototyp. J. 13, 3 (2007)

30. W. Zhong, F. Li, Z. Zhang, et al., Mater. Sci. Eng. A 301, 2 (2001)

31. T. Ramanathan, A.A. Abdala, S. Stankovich, et al., Nat. Nanotechnol. 3, 6 (2008)

32. T. Ramanathan, S. Stankovich, D.A. Dikin, et al., J. Polymer Sci. Part B-Polymer Phys. 45, 15 (2007)

33. S. Vadukumpully, J. Paul, N. Mahanta, et al., Carbon 49, 1 (2011)

34. C. Heo, H.G. Moon, C.S. Yoon, et al., J. Appl. Polym. Sci. 124, 6 (2012)

35. Q.F. Xu, B. Mondal, A.M. Lyons, ACS Appl. Mater. Interfaces 3, 9 (2011)

36. M. Faes, H. Valkenaers, F. Vogeler, et al., in 3rd Cirp Global Web Conference Production Engineering Research Advancement beyond State of the Art, ed. by A. Caggiano, vol 28 (2015), p. 76

37. H.W. Lin, C.P. Chang, WH Hwu et al. J. Mater. Process. Technol. 197, 1-3 (2008)

38. S.M. Lebedev, O.S. Gefle, E.T. Amitov, et al., Polym. Test 58 (2017)

39. K. Gnanasekaran, T. Heijmans, S. van Bennekom, et al., Appl. Mater. Today 9 (2017)

40. Y.C. Jia, H. He, Y. Geng, et al., Compos. Sci. Technol. 145 (2017)

41. C. Shemelya, A. De La Rosa, A.R. Torrado, et al., Addit. Manuf. 16 (2017)

42. E. Pop, V. Varshney, A.K. Roy, MRS Bull. 37, 12 (2012)

43. J.D. Renteria, D.L. Nika, A.A. Balandin, Appl. Sci.-Basel 4, 4 (2014)

44. A.A. Balandin, Nat. Mater. 10, 8 (2011)

45. J.W. Jiang, B.S. Wang, J.S. Wang, et al., J. Phys. Condens. Matter 27, 8 (2015)

46. G. Chen, Int. J. Therm. Sci. 39, 4 (2000)

47. C. Yuan, B. Xie, M. Huang, et al., Int. J. Heat Mass Transf. 94 (2016)

48. P. Zhao, K. Wang, H. Yang, et al., Polymer 48, 19 (2007)

49. E.T. Thostenson, T.W. Chou, J. Phys. D-Appl. Phys. 35, 16 (2002)

50. D. Zhang, B.H. Chi, B.W. Li, et al., Synth. Met. 217 (2016)

51. D.C. Zhu, Y.Y. Ren, G.X. Liao, et al., J. Appl. Polym. Sci. 134, 39 (2017)

52. G. Liao, Z. Li, Y. Cheng, et al., Mater. Des. 139 (2018)

53. A. Dorigato, V. Moretti, S. Dul, et al., Synth. Met. 226 (2017)

54. R. Singh, G.S. Sandhu, R. Penna, et al., Materials 10, 8 (2017)

55. B.G. Compton, B.K. Post, C.E. Duty, et al., Addit. Manuf. 17 (2017)

56. O.S. Carneiro, A.F. Silva, R. Gomes, Mater. Des. 83 (2015)

57. N. Burger, A. Laachachi, M. Ferriol, et al., Prog. Polym. Sci. 61 (2016)

58. L.J. Love, V. Kunc, O. Rios, et al., J. Mater. Res. 29, 17 (2014)

59. Y. Zhuang, W.T. Song, G. Ning, et al., Mater. Des. 126 (2017)

60. J. Jyoti, S. Basu, B.P. Singh, et al., Composites Part B-Engineering 83 (2015)
61. G. Postiglione, G. Natale, G. Griffini, et al., Composites Part A-Appl. Sci. Manufacturing 76 (2015)

62. S.J. Leigh, R.J. Bradley, C.P. Purssell, et al., PLoS One 7, 11 (2012)

63. J. Czyzewski, P. Burzynski, K. Gawel, et al., J. Mater. Process. Technol. 209, 1213 (2009)

64. J.F. Christ, C.J. Hohimer, N. Aliheidari, et al., in Sensors and Smart Structures Technologies for Civil, Mechanical, and Aerospace Systems 2017, ed. by J. P. Lynch, vol 10168 (2017)

65. X.H. Yao, C.C. Luan, D.M. Zhang, et al., Mater. Des. 114 (2017)

66. JM Gardner, G Sauti, JW Kim et al., Additive Manufacturing 12, (2016)

67. W.W. Yu, J. Zhang, J.R. Wu, et al., J. Appl. Polym. Sci. 134, 15 (2017)

68. D.P. Schmitz, L.G. Ecco, S. Dul, et al., Materials Today Communications 15 (2018)

69. C.W. Foster, M.P. Down, Y. Zhang, et al., Sci. Rep. 7 (2017)

70. V.B. Mohan, B.J. Krebs, D. Bhattacharyya, Materials Today Communications $17(2018)$

71. G Tsiakatouras, E Tsellou, and C Stergiou, 12, (2014)

72. R. Matsuzaki, M. Ueda, M. Namiki, et al., Sci. Rep. 6 (2016)

73. M.L. Shofner, K. Lozano, F.J. Rodriguez-Macias, et al., J. Appl. Polym. Sci. 89, 11 (2003)

74. M. Plymill, Greeley, et al., University of Tennessee Honors Thesis Projects (2016)

75. F.D. Ning, W.L. Cong, J.J. Qiu, et al., Composites Part B-Engineering 80 (2015)

76. T. Hofstätter, W.I. Gutmann, T. Koch, et al., Proceedings of ASPE Summer Topical Meeting 2016: Dimensional Accuracy and Surface Finish in Additive Manufacturing ASPE - The American Society for Precision Engineering (2016)

77. H.L. Tekinalp, V. Kunc, G.M. Velez-Garcia, et al., Compos. Sci. Technol. 105 (2014)

78. W.F. Hao, Y. Liu, H. Zhou, et al., Polym. Test. 65 (2018)

79. N.Y. Li, Y.G. Li, S.T. Liu, J. Mater. Process. Technol. 238 (2016)

80. B.G. Compton, J.A. Lewis, Adv. Mater. 26, 34 (2014)

81. K. Fvd, Y. Koga, A. Todoroki, et al., Open J. Compos. Mater. 6 (2016)

82. K.I. Mori, T. Maeno, Y. Nakagawa, in 11th International Conference on Technology of Plasticity, Ictp 2014, ed. by T. Ishikawa, K. I. Mori, vol 81 (2014), p. 1595

83. X.Y. Tian, T.F. Liu, Q.R. Wang, et al., J. Clean. Prod. 142 (2017)

84. J. Bustillos, D. Montero, P. Nautiyal, et al., Polym. Compos. 39, 11 (2018)

85. T.F. Liu, X.Y. Tian, M.Y. Zhang, et al., Composites Part A-Appl. Sci. Manufacturing 114 (2018)

86. S. Berretta, R. Davies, Y.T. Shyng, et al., Polym. Test. 63 (2017)

87. J. Justo, L. Tavara, L. Garcia-Guzman, et al., Compos. Struct. 185 (2018)

88. Q.Y. Chen, J.D. Mangadlao, J. Wallat, et al., ACS Appl. Mater. Interfaces 9, 4 (2017)

89. D.G. Papageorgiou, M.F. Liu, Z.L. Li, et al., Compos. Sci. Technol. 175 (2019)

90. N. Kumar, P.K. Jain, P. Tandon, et al., J. Braz. Soc. Mech. Sci. Eng. 40, 4 (2018)

91. K. Prashantha, F. Roger, J. Macromol. Sci. Part A-Pure Appl. Chem. 54, 1 (2017)

92. S. Dul, L. Fambri, A. Pegoretti, Nanomaterials 8, 1 (2018)

93. T. Batakliev, V. Georgiev, E. Ivanov, et al., J. Appl. Polym. Sci. 136, 13 (2019)

\section{Publisher's Note}

Springer Nature remains neutral with regard to jurisdictional claims in published maps and institutional affiliations.

\section{Submit your manuscript to a SpringerOpen ${ }^{\odot}$ journal and benefit from:}

- Convenient online submission

- Rigorous peer review

- Open access: articles freely available online

- High visibility within the field

- Retaining the copyright to your article

Submit your next manuscript at $>$ springeropen.com 